\title{
Where is the voice of social work in the multi disciplinary palliative care team?
}

\section{Mary James}

Mary James is a social worker for the Nelson Region Hospice Trust.

\begin{abstract}
In the medical world, audits are frequently conducted to assess performance ideals and generate better outcomes for staff and patients. Audits are not such a common measure in social work. In order to begin to find a place to articulate the value of social work within the work of Hospice, a snapshot survey was taken of referrals within Hospice programmes within a specified three month period.
\end{abstract}

The results of the audit revealed some striking commonalities as well as variations which may reflect the communities the Hospices operate within.

The results of four other audits taken within the social work literature are presented. Snapshot 'quotes' taken from international researchers set a foundation for social workers to articulate the value of their role within palliative care. It is argued that unless social workers begin to articulate the value of their skills, they are in danger of becoming a forgotten voice in the multi disciplinary team caring for the needs of Hospice patients and families.

\section{Introduction}

In New Zealand, palliative care is defined as 'care for people of all ages with a life limiting illness which aims to:

1. Optimise an individual's quality of life until death by addressing the person's physical, psychosocial, spiritual and cultural needs

2. Support the individual's family, whanau, and other carers where needed, through illness and after death (Hospice New Zealand, 2011, p.8).

This article explores the place of social work within palliative care through auditing the number of social work referrals compared to the number of referrals to Hospice within the same three month period. It also reviews literature surrounding social work and palliative care auditing, and makes some recommendations towards the development of a Hospice policy which includes the role of social work.

Standard 12 of the Hospice Palliative Care Standards states; 'The service is committed to quality improvement and research in clinical and management practices' (Hospice New Zealand, 2011, p.23). 
It can be argued that unless any Hospice is seeking to review and assess the service that it offers to palliative care patients, this Standard is meaningless without a specific context being specified. An audit theoretically measures practice realities against a standard of practice with clearly defined boundaries. If Standards are not in place, they are unable to be measured. It further challenges all practitioners to continue to develop skills, knowledge and expertise in their chosen field of practice in order to meet the constantly changing demands that arise in palliative care.

I was only able to find four journal articles relating to social work and palliative care audits published within the past five years. They are:

1. Levy and Payne's (2006) study focused on the need for specialised welfare rights advocacy service to sit alongside the social work team in a Hospice setting.

2. Following the introduction of an adult protection service policy in the United Kingdom, Payne (2007) audited the effectiveness of social work assessment and intervention over a two year period in one palliative care service.

3. Reith and Lucas (2008) questioned the benefits of transferring patients into rest home care at the end of life from Hospice settings.

4. Pockett, Walker and Dave (2010) conducted a study in Australia with the purpose of gaining increased understanding around what was happening at end of life care in a hospital setting and how social work was utilised.

\section{Social work audit}

This audit looks at the total number of referrals made to the Hospice in the area in which I work over the three month period from 1 May to 31 July 2011, and compares that with the number of referrals made for social work support in that same time. In order to obtain some perspective of how the Hospice in which I work compares with other Hospices around New Zealand, I sent a 'snapshot' questionnaire to all the Hospices in New Zealand. (Refer Appendix 1). I received nine replies and the data is to be collated and information drawn from those replies.

Table one presents the feedback I received from nine different Hospices to the above questions. In order to preserve anonymity, each Hospice is given a number for identification purposes.

It is interesting to note that Hospice 1 and Hospice 9 both have a practice understanding where any referral to Hospice automatically implies an associated referral for social work support as part of the Interdisciplinary Team. It is the practice philosophy of Hospice 9 for both a Hospice nurse and a member of the allied health team to jointly visit for the admission interview of a family to their Service. Usually this team member would be a social worker, however it may be the Chaplain or a counsellor who will attend the initial visit, depending on the known needs of the family when referred to the Hospice. Their Service reports that $65 \%$ percent of the time they are able to conduct joint visits. Where an allied health team member is not able to attend the first meeting with the family, a social worker will visit at the first available opportunity. All families are assessed in regard to their psychosocial needs.

Hospice 3 reported that they did not have a social worker employed by their Hospice and were currently in the process of developing a business plan to secure funding to develop this aspect of their Service. 
Table one. Total number of referrals to Hospive and referrals for social work support, 1 May-31 July 2011.

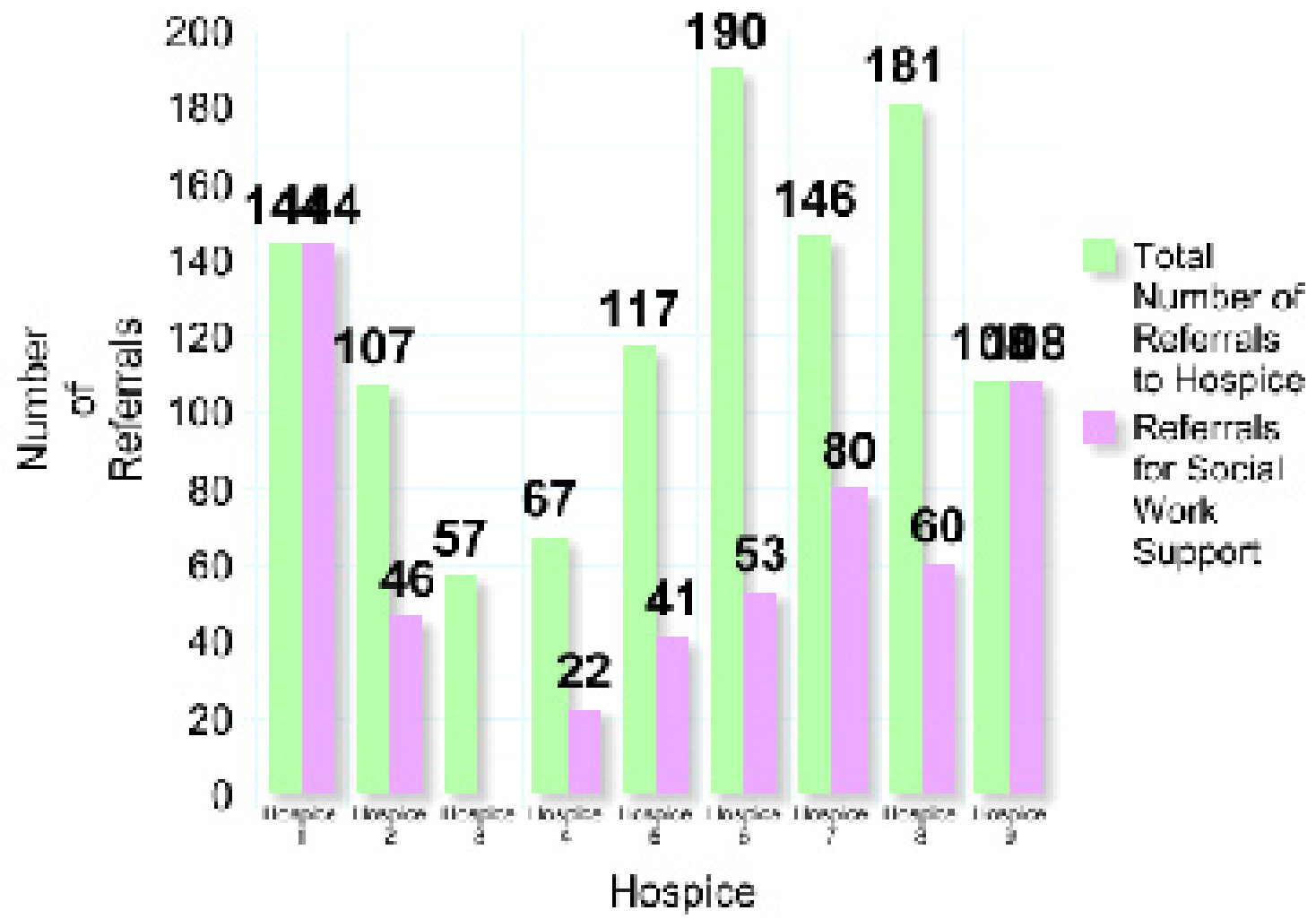

Both Hospice 4 and Hospice 8 identified separate referral numbers for their rural families. Those numbers have been included in the total number of referrals to each Hospice. In the case of Hospice 4, the social worker responds to referrals made via the District Nurses. For Hospice 8, referrals are more commonly made to the community social worker in each rural community, with the Hospice social workers providing a more consultative role.

Hospice 6 has a policy where all referrals are made to Family Support Services, prior to being triaged and allocated to appropriate members of that team.

Four Hospices were able to provide figures on reasons given for the initial referral. These are diagrammatically displayed as shown in Table two.

Across the four Hospices who provided data, it is interesting to note that financial matters, rest home referrals, and personal and community support make up the greatest number of reasons for initial referral. Without further research, it is not possible to quantify how and why the differences exist, particularly as each Hospice has a range of duties that are assigned to their social workers. However these same duties may vary between Hospices, depending on how each Hospice is structured. For example: some Hospices assign Rest Home Assessments to nursing staff to complete; others assign this to social work staff to complete. Some Hospices have a separate Bereavement Service; others incorporate Bereavement Support into their social work portfolio. Some Hospices refer all relationship and personal support issues to their counsellors; others may share this task between social workers and counsellors, depending on the presenting needs of the family. 


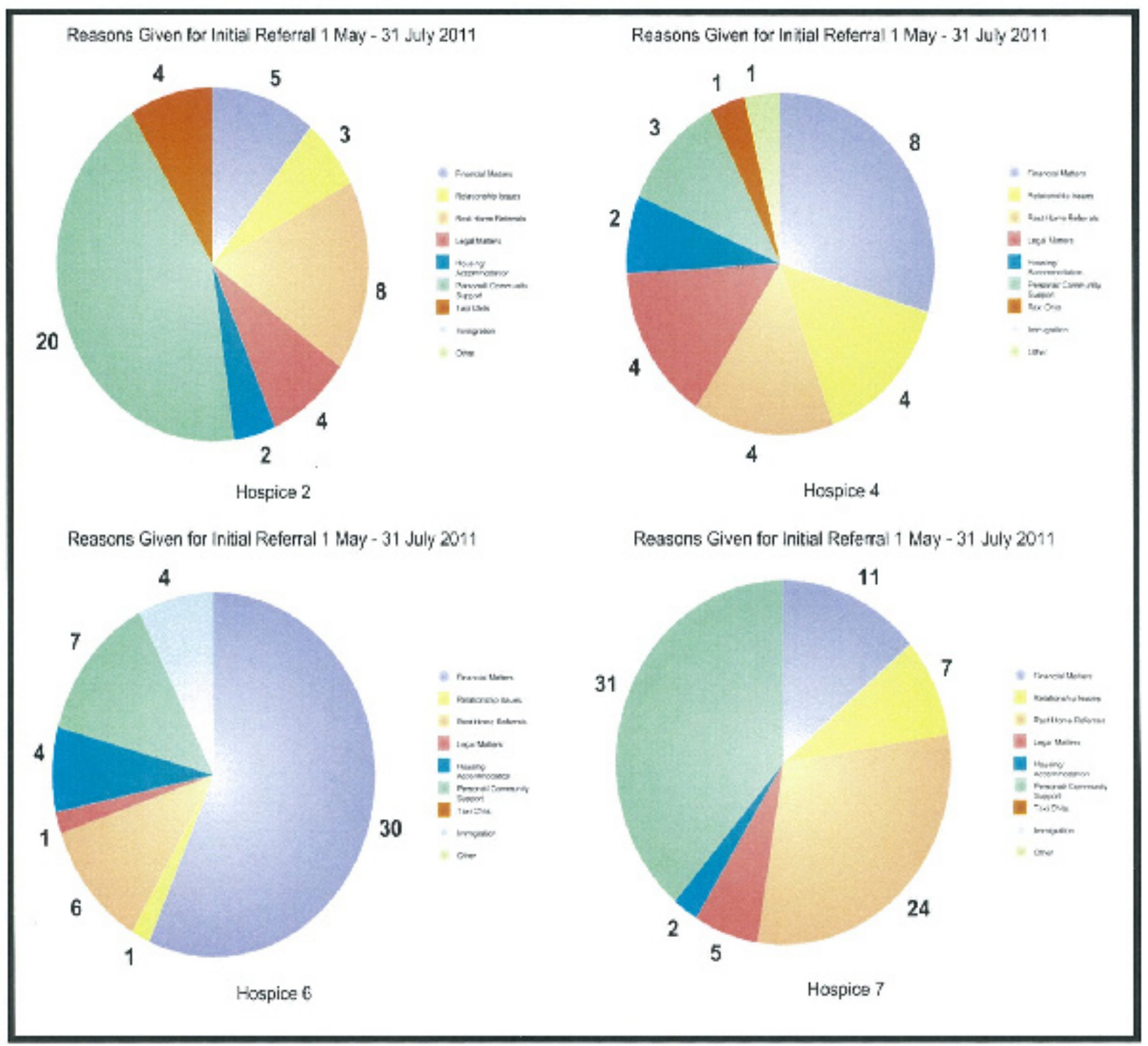

In regard to having a policy for how social work was utilised within each Hospice, only three Hospices were able to confirm that they had such a policy. Another Hospice had a policy regarding how social workers transitioned patients transferring from hospital to Hospice care.

\section{Social work literature}

In exploring the literature around social work and palliative care, a need to advocate more clearly around the skills of social work has emerged. Berzoff (2008) describes what she considers to be an essential skill in psychosocial work at end-of-life. '(It) requires being in a relationship with a client and family, located within their culture, religion and beliefs, in which the clinician is able to tolerate a range of affects, including her own anxiety' (p.179). She further identified a key role for social workers in standing in the gap between families and the medical profession, both facilitating and mediating between both roles. 
In seeking to give voice to the role of the social worker within the palliative care team, Higgins (as cited in Meier \& Beresford, 2008a) states:

Social workers in palliative care need to make themselves heard, which can be frustrating at times. The key is communication ... You need to manage personalities ... Social workers need to make themselves visible and conduct joint visits. Sometimes it's easier to show than to say what I can contribute. I get more buy-in after other team members watch me work and see in practical, concrete ways what I'm doing that's specialised and different - and the impact it has' (p. 11).

O'Connor and Fisher (2011) identified psychosocial care as the domain where tensions were most likely to be found for interdisciplinary palliative team members. They found 'the blurring of role boundaries and the provision of psychosocial care by members of the team was perceived as being positive by nonspecialist psychosocial team members and as unsatisfactory, frustrating, and even potentially harmful, by specialist psychosocial team members.' (p.194). This has the potential to cause division in the interdisciplinary team and inhibit the team's ability to work effectively and cohesively together.

Meier and Beresford (2008b) state the need to acknowledge the 'historical imbalance in power and responsibility between physicians and psycho-social-spiritual professionals.' (p.679). They quote Stadler, the Programme Director of Clinical Services in Hanover, New Hampshire, 'Our pastoral care and social work colleagues are integral members of the interdisciplinary team. However it has been a challenge to get medical palliative care providers to let go of certain things and to pass the baton to other professionals ...' (p.679).

Within the literature, there is an acknowledged need to include the views of service user's in the broader picture of how palliative care operates and functions. Beresford, Croft \& Adshead (2008) did precisely this, with a particular focus on social work. They found that whilst people generally had a positive experience of their interactions with social workers, a wider issue emerged indicating the way social work was structured and managed within the palliative care service itself had the potential to limit the effectiveness of social work interactions.

... the very things that service users emphasise as special and important are not, more generally, seen as such... what service users see as strengths and positives of social work practice may, in fact, be factors which reduce the likelihood of it being afforded external recognition. We encountered a number of issues and characteristics associated with specialist palliative care social work which seem to reinforce such a view. These include:

- the strong 'hands-on' aspect of specialist palliative care social work;

- its commitment to partnership with patients;

- the breadth of its remit;

- an emphasis on demystification;

- accessibility and flexibility;

- association with friendship and friendliness;

- avoidance of jargon.

All of these may have an adverse effect on how far specialist palliative care social work is seen to demarcate a 'profession' in its own right, with it's own distinct body of knowledge, area of expertise, skills, values and competence... what our study indicated was that this was how service users predominantly saw it - and valued it, as a profession with a particular contribution 
to make, not offered by other professions and occupations, one which they repeatedly reported could make a major positive impact on their lives' (Beresford et al., 2008, p.1403).

Bosma, Johnson, Cadell, Wainwright, Abernathy, Feron, Kelley and Nelson (2010) acknowledged the arguments made by previous authors, stating the role and functions of social workers within palliative care lacked clarity which '... has contributed to boundary and role issues between social workers and other health care professional, particularly nurses and physicians' (p. 80). They further argued that '... it is crucial for the social work profession to coherently identify and outline its roles and competencies so that social work practice can be advanced in Hospice Palliative Care' (p. 80).

To achieve this they identified the core competencies necessary for palliative care social workers.

They include advocacy, assessment, care delivery, care planning, community capacity building, evaluation, decision-making, education and research, information sharing, interdisciplinary teamwork and self-reflective knowledge. Each competency is described according to the values, knowledge, and skills significant to it (Bosma, et al., 2008, p. 2).

The beauty of the competencies is their flexibility to be used as a framework to guide practice within a range of settings. It is not a 'one size fits all' recipe, rather a tool to be used to enable each Hospice to decide which are the core competencies and roles that are important to how they wish social work to be incorporated into its Service.

\section{Social work and palliative care audit literature}

1. Following an audit of the provision of a specialised welfare rights advocacy service within a Hospice Service in the United Kingdom, Levy and Payne (2006) found that there was a significant need for specialised advocacy to enable some families to negotiate their full entitlement to financial support. Where families had their financial needs met, this significantly improved the families' ability to manage the stresses of a terminally ill family member.

In my work, I have found that many families are able to manage with support from Work and Income. One of the key issues is knowing how to negotiate the process of applying for income support. It is also knowing what type of support people are entitled to apply for. As a generalisation, families who have been financially independent prior to becoming Hospice patients, sometimes struggle to adapt to a significantly lower income when transitioning onto a benefit. Equally, families who have been on a low income may have fewer resiliencies to absorb some of the expenses that are associated with adapting to a terminal illness. Whilst medical care may be at a low cost or free, associated travel, hosting family members and accommodating health needs comes at a cost. Those who struggle with debt prior to becoming ill are not always able to manage this when unwell. For specialised benefit advice and advocacy in New Zealand there is a network of Beneficiary and Low Income Advisory Services.

An associated issue in regard to financial support and management is that often people may be reluctant to bring financial concerns up as an issue. I have observed that it is whilst patients are in the In Patient Unit for other matters, that financial concerns may 
arise as an issue. A number of referrals I receive that have come from the In Patient Unit are for this reason. However, for some families, it can be that the time available between accessing information about financial support and achieving it through entitlements to additional support may be too small. I would suggest that as a matter of practice, all families who come into the Hospice Service are offered an interview with their Hospice Social Worker who can discuss and give appropriate information in this regard. I would also anticipate this including a discussion about Powers of Attorney.

2. Payne (2007) conducted an audit on how a United Kingdom Hospice Service provided support for adults either in abusive relationships or at risk of abuse and neglect at end of life. The audit was of notifications made over a two year period following the introduction of an Adult Protection Policy in the United Kingdom.

Through analysis of factors highlighting concern, Payne (2007) identifies a key ingredient in potentially abusive complaints being made, namely, difficult family relationships were compounded by the approaching end-of-life needs that the vulnerable family member was experiencing. He found abuse occurred to both men and women. He also indentified the following risk factors:

i) a history of alcohol and drug abuse;

ii) a history of mental health concerns may predispose a party to being vulnerable to abuse at end-of-life;

iii) disagreement over the level and type of care being provided with a consequent withholding or redirection of funding.

Despite complaints of abuse, it was reported that while the majority of people being abused wanted support and intervention, there were a number of people who did not want to disrupt their caring relationship.

In the Hospice where I work we certainly encounter families where abuse and neglect occur. It is my opinion that when we, as a team, are aware of abuse and neglect, we generally work strongly and cohesively in a true interdisciplinary manner together. In instances where we do not work closely together, splitting within the team is the biggest risk to be able to work effectively. Splits generally tend to occur over emotional and ethical issues. The splitting can reflect splits that are within the family, and be motivated by strong emotional attachments to a position taken by a family member over an issue. Team members tend to view family issues through the particular 'lens' that they were taught during their professional training. Depending on the profession we each practice (nursing, medicine, social work, counselling) we may see and interpret issues differently.

There are two tools I have discovered which I believe would enhance our ability to work alongside families who are experiencing abuse and/ or neglect. Bergeron's (2004) Classification of Elder Abuse Table (which closely resembles the one used by Age Concern (2002) in New Zealand) and Bomba's (2006) screening tool each give clear definitions of abuse and neglect. Through identifying the type of abuse one is encountering, it is possible to put an appropriate support and management plan into place around individuals and families. 
3. Reith and Lucas (2008) conducted an audit of outcomes of transitioning family members into rest home care at the end of life. Their argued that:

...if the aim of palliative care is to achieve quality of life and a dignified death, preferably in a place of the patient's choosing, nursing home transfers at this late stage of life and contrary to people's wishes and best interests must be questionable (Porock et al., cited in Reith \& Lucas, 2008, p.234).

In the Hospice audited, just under $7 \%$ of people admitted to the Hospice were considered for referral for rest home care. Of this number, only one quarter of those referred were admitted to a rest home. It was found that $63 \%$ of patients included in the audit died within six weeks of admission to Hospice, irrespective of where they spent their final days.

It was further identified that where rest home care had been introduced for discussion, the patient and his / her family recognised that discharge from an In Patient Unit was being considered and the patient was unlikely to manage well at home independently. Of those people with whom this conversation was held, 33\% lived alone, and $66 \%$ had family members who felt unable to continue caring for their family member.

As well as considering medical reasons for transfer into rest home care, Reith and Lucas (2008) advocated for the decision to consider rest home care to take into account the patient, the family and the perceived bereavement consequences of each decision that is proposed. They argue that to do this in a truly palliative manner requires the involvement of all members of the interdisciplinary team.

In the Hospice where I work, there is a process which takes place when considering discharge from the In Patient Unit. A discussion is had between the Hospice Medical Officer and the Clinical Team Leader to determine whether the person requiring care has generalist or specialist palliative care needs. Prior to any definitive decision being made, a family meeting will be held to discuss 'where to from here' and involve the family in the decision making process. Other team members may be brought in to discuss issues and provide support around rest home transfer if that is the agreed place of care. There are two long term Hospice beds available for those who have specialist palliative care needs. Those who do transfer to rest home care continue to have regular visits from members of the Hospice Service. The decision regarding the provision of specialist palliative care is able to be revisited if a patient's circumstances change.

4. Pockett, Walker \& Dave (2010) conducted an audit on the utilisation of social work services at end of life in a hospital setting in Australia. They found $36 \%$ of patients had a social worker involved in their final admission to hospital. However, in reviewing patient files, it was found that many patients had social work involvement during their association with the hospital, suggesting that social workers were more likely to be involved with patients who had a longer association with the hospital due to previous admissions.

The authors identified three roles of social work at end of life as:

i) assisting to establish the reliability of surrogate decision making;

ii) mediating between family members in the event of disagreement; and

iii) advocating on behalf of the patient and family with the medical team. 
It is acknowledged that:

... underpinning social work practice is an ability to accept and work with diversity, uncertainty, and ambiguity and interpret the social and ethical context in which decisions are being made to ensure the rights and values of dying patients and their families are being respected (Pockett, et al., 2008, p. 262.)

It is also acknowledged that guidelines need to be developed that contribute to the awareness of all members of the interprofessional team to the issues raised above. Clausen, Kendall, Murray, Worth, Boyd and Benton (2005) support early inclusion of a social worker in the care team of terminally ill patients as offering the following benefits:

i) ability to establish a longer-term relationship with the patient and family;

ii) assessment and offering of advice and provision of early interventions according to individual need; and

iii) collegial support as an integral member of the interdisciplinary team.

They further argue that were social workers to be included early in the process (as opposed to when a crisis occurs); this might help more people to die in the place of their choice.

With regard to surrogate decision making, a referral for social work is one avenue where it is possible to begin to break open questions about care preferences, about future decision making, about guardianship and care issues for other family members who will be impacted by the ill health and death of a loved one. I have found that when these opportunities arise, it often enables the family to consider and play around with options prior to committing to a plan of action.

\section{Discussion}

The purpose of this article was to audit an area of practice within the Hospice I work in relation to Standard 12 of the Hospice Palliative Care Standards (pilot version) April 2011 which states 'The Service is committed to quality improvement and research in clinical and management practices.' Hospice NZ, (2011 p.23).

In this article I have looked at the number of referrals made to Hospice and compared it to the number of referrals made to social work within the same time period. I have illustrated the referrals by way of graphs to show how different Hospices utilise their social workers. In Table three, I have translated those results into percentages. Excluding Hospices 1, 3 and 9; it shows between 28 and 55\% of the patients are referred to social workers employed in Hospice.

It seems clear that for social work to be better incorporated as part of the palliative care interdisciplinary team, it may be necessary to consider some adjustments to how this service is currently provided within each Hospice. It may also be necessary to acknowledge that any changes made to the current environment social workers are engaged in may involve changes at an organisational level and a shift in thinking as to what social work is (Beresford, et al., 2008; Bosma, et al., 2008; Clausen, et al., 2008). 


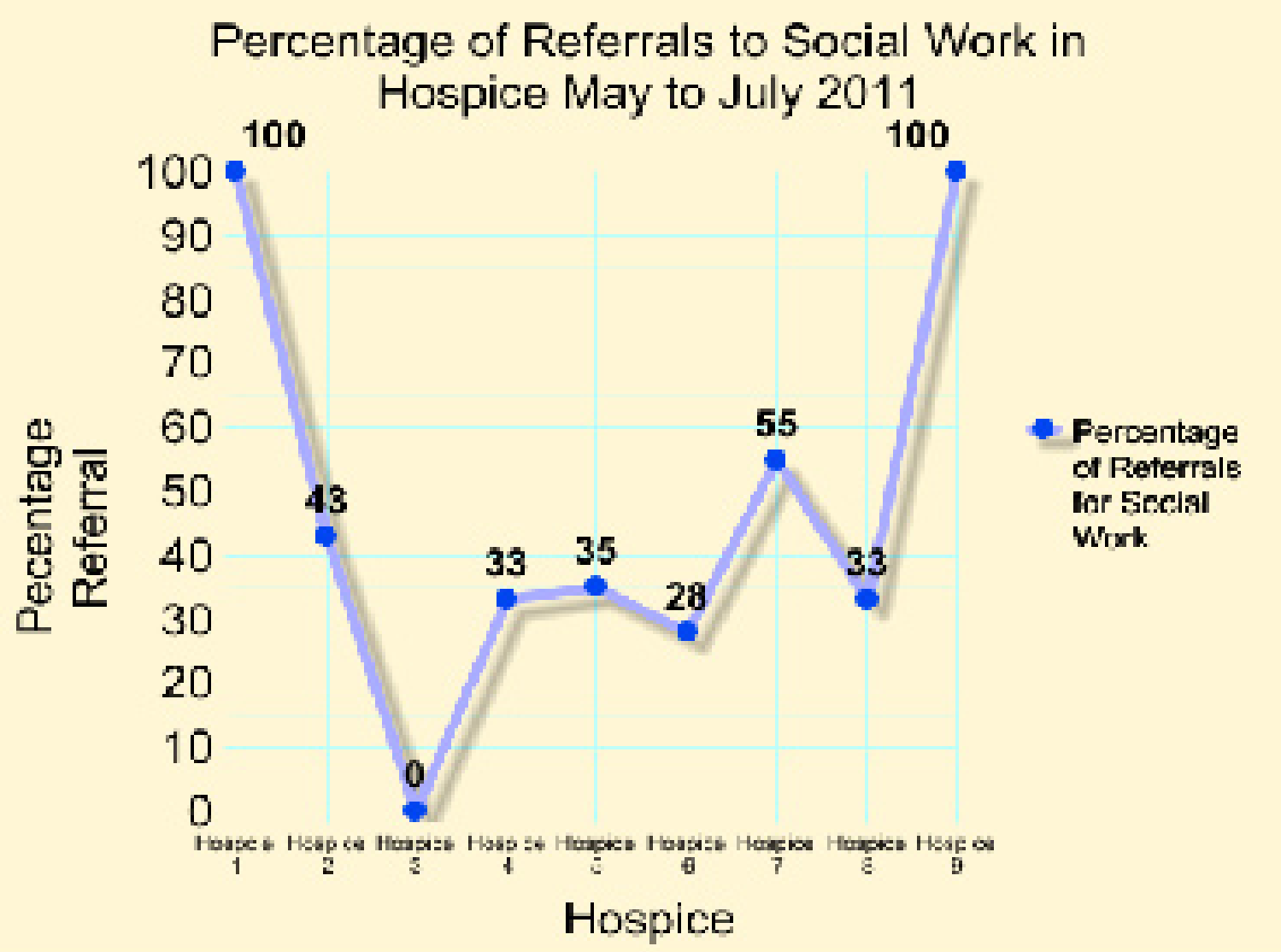

Prior to this occurring, I believe that a discussion as to how each Hospice wishes to structure the social worker service within their organisation needs to take place. From there a policy for social work could be developed to suit both the Hospice organisationally, and the community in which it operates. A key document to assist with that discussion is the Canadian Social Work Competencies for Hospice Palliative Care by Bosma, et al. (2008):

...the direct application of these competencies will vary across settings and for different practitioners. This variability reflects the reality of different levels of education and training among social workers, as well as different job descriptions and resources that exist across care sites and geographic locations... (p. 2).

Some of the questions that could be asked are:

i) What are the competencies we want for social work in our Hospice?

ii) How do we see this working?

iii) Where are the current gaps in social work in our Hospice?

Once this is done, and a policy is developed, then each Hospice will be in a position to reflect upon what is occurring with the social work referrals within their organisation. 


\section{Social Work Audit}

Please will you assist me with my audit by providing the following information for me?

1. Total number of referrals to Hospice for the period 1 May to 31 July $2011 \ldots \ldots \ldots$. . .

2. Number of referrals made for social work support for the period 1 May to 31 July 2011 ............

3. Breakdown of the initial reasons given for referral:

i) financial matters

ii) relationship issues

iii) rest home referrals

iv) legal matters.

v) housing / accommodation

vi) personal support

vii) community support.

viii) taxi chits

ix) Other (please list).....

It is fine to fill this part out as a tally chart - some referrals cover a range of groupings. I have not written advocacy as a separate heading as we advocate in respect of a range of issues eg finances, housing, legal matters.

4. My Hospice has a written policy for making social work referrals. Yes / No. Please attach a copy if you do have one.

5. Name.

6. Position

7. Name of Hospice

I am happy to give some feedback once I have put all this information together. Please could you return this information back to me by 7 September 2011.

Thank you in anticipation of your assistance.

\section{Reference}

Age Concern New Zealand. (2002). What is elder abuse? Retrieved from http:/ / www.ageconcern.org.nz/safety / elder-abuse / what-elder-abuse 22/11/ 12

Beresford, P., Croft, S., \& Adshead, L. (2008). 'We don't see her as a social worker': a service user case study of the importance of the social worker's relationship and humanity. British Journal of Social Work, 38, 1388-1407.

Bergeron, L.R. (2004). Elder abuse: clinical assessment and obligation to report. In K.A. Kendall-Tackett (Ed). Health consequences of abuse in the family: a clinical guide for evidence-based practice. Washington DC, US: American Psychological Association, 109-128. 
Berzoff, J. (2008). Working at the end of life: providing clinically based psychosocial care. Clinical Social Work Journal, 37,177-184.

Bomba, P.A. (2006). Use of a single page elder abuse assessment and management tool: a practical clinician's approach to identifying elder mistreatment. Journal of Gerontological Social Work, 46(3/4), 103-122.

Bosma, H., Johnston, M., Cadell, S., Wainwright, W., Abernathy, N., Feron, A., $\quad$ Kelley, M.L., \& Nelson, F. (2008). Canadian social work competencies for hospice palliative care: A framework to guide education and practice at the generalist and specialist levels. Retrieved from http:/ / www.chpca.net/interest groups / social workers-counsellors / socialwork counsellors competencies.html 2008. 1-19

Bosma, H., Johnston, M., Cadell, S., Wainwright, W., Abernathy, N., Feron, A., Kelley, M.L., \& Nelson, F. (2010). Creating social work competencies for practice in hospice palliative care. Palliative Medicine, 24(1), 79-87.

Clausen, H., Kendall, M., Murray, S., Worth, A., Boyd, K., \& Benton, F. (2005). Would palliative care patients benefit from social workers' retaining the traditional 'casework' role rather than working as care managers? A prospective serial qualitative interview study. British Journal of Social Work, 35, 277-285.

Hospice New Zealand (2011). Hospice New Zealand Standards for the care of people approaching the end of life (pilot version). April 2011, 1-29.

Levy, J. \& Payne, M. (2006). Welfare rights advocacy in a specialist health and social care setting: a service audit. British Journal of Social Work, 36, 323-331.

Meier, D.E. \& Beresford, L. (2008a). Social workers advocate for a seat at palliative care table. Journal of Palliative Medicine, 11(1), 10-14.

Meier, D.E. \& Beresford, L. (2008b). The palliative care team. Journal of Palliative Medicine, 11(5), 677-681.

O'Connor, M. \& Fisher, C. (2011). Exploring the dynamics of interdisciplinary palliative care teams in providing psychosocial care; 'Everybody thinks they can do it and they can't.' Journal of Palliative Medicine, 14(2), 191-196.

Payne, M. (2007). Safeguarding adults at end of life: audit and case analysis in a palliative care setting. Journal of Social Work in End-of-Life and Palliative Care, 3(4), 31-46.

Pockett, R., Walker, E., \& Dave, K. (2010). 'Last orders': dying in a hospital setting. Australian Social Work, 63(3), 250-265.

Reith, M. \& Lucas, C. (2008). Questioning the evidence for service assumptions: audit of transfers from a hospice to nursing home care. Journal of Social Work, 8(3), 233-245. 